\title{
Mortality of hospitalised internal medicine patients bedspaced to non-internal medicine inpatient units: retrospective cohort study
}

\author{
Anthony D Bai, ${ }^{1}$ Siddhartha Srivastava, ${ }^{1}$ George A Tomlinson, ${ }^{2}$ \\ Christopher A Smith, ${ }^{1}$ Chaim M Bell, ${ }^{3}$ Sudeep S Gill ${ }^{1}$
}

- Additional material is published online only. To view please visit the journal online (http://dx.doi.org/10.1136/ bmjqs-2017-006925).

'Department of Medicine, Queen's University, Kingston, ON, Canada

${ }^{2}$ Department of Medicine University of Toronto, Toronto, ON, Canada

${ }^{3}$ Department of Medicine, Sinai Health System and University of Toronto, Toronto, ON, Canada

\section{Correspondence to} Dr Sudeep S Gill, Department of Medicine, Queen's University, 752 King St. West Kingston ON Canada K7L 4X3; ssg@queensu.ca

Received 18 May 2017 Revised 6 October 2017 Accepted 20 October 2017 Published Online First 3 November 2017

\section{SLinked}

- http://dx.doi.org/10.1136/ bmjqs-2017-007524

CrossMark

To cite: Bai $A D$, Srivastava $S$, Tomlinson GA, et al.

BMJ Qual Saf 2018;27:11-20.

\section{ABSTRACT}

Objective To compare inhospital mortality of general internal medicine (GIM) patients bedspaced to off-service wards with GIM inpatients admitted to assigned GIM wards.

Method A retrospective cohort study of consecutive GIM admissions between 1 January 2015 and 1 January 2016 was conducted at a large tertiary care hospital in Canada. Inhospital mortality was compared between patients admitted to off-service wards (bedspaced) and assigned GIM wards using a Cox proportional hazards model and a competing risk model. Sensitivity analyses included propensity score and pair matching based on GIM service team, workload, demographics, time of admission, reasons for admission and comorbidities. Results Among 3243 consecutive GIM admissions, more than a third $(1125,35 \%)$ were bedspaced to off-service wards with the rest $(2118,65 \%)$ admitted to assigned GIM wards. In hospital, 176 (5\%) patients died: 88/1125 (8\%) bedspaced patients and 88/2118 (4\%) assigned GIM ward patients. Compared with assigned GIM wards patients, bedspaced patients had an HR of $3.42(95 \% \mathrm{Cl} 2.23$ to 5.26; $P<0.0001)$ for inhospital mortality at admission, which then decreased by HR of 0.97 ( $95 \% \mathrm{Cl} 0.94$ to 0.99 ; $\mathrm{P}=0.0133$ ) per day in hospital. Competing risk models and sensitivity analyses using propensity scores and pair matching yielded similar results.

Conclusions Bedspaced patients had significantly higher inhospital mortality than patients admitted to assigned GIM wards. The risk was highest at admission and subsequently declined. The results of this single centre study may not be generalisable to other hospitals and may be influenced by residual confounding. Despite these limitations, the relationship between bedspacing and patient outcomes requires investigation at other institutions to determine if this common practice represents a modifiable patient safety indicator.

\section{INTRODUCTION}

Hospital capacity strain negatively impacts quality of care. ${ }^{1}$ Overcrowding creates many challenges to efficient patient navigation of the hospital system from initial assessment in the emergency department (ED), to admission onto inpatient wards, and ultimately to patient discharge.
Beginning in the ED, overcrowding is associated with delayed care and reduced survival. ${ }^{2}$ After admission, patients may then become 'boarders', who remain in EDs after admission while awaiting inpatient beds. ED boarding delays medical care, prolongs length of stay and may increase mortality. ${ }^{3-6}$

When assigned general internal medicine (GIM) ward beds become fully occupied, new patients are often 'bedspaced', meaning they are admitted to off-service inpatient units to free up ED beds. ${ }^{78}$ This is a common occurrence across hospitals. ${ }^{8}$ Bedspaced patients reside in areas of the hospital away from assigned GIM wards where medical team members responsible for their care are usually located. Allied health services (eg, nursing, physiotherapy) for bedspaced patients are typically delivered by the 'host service', and they may have limited contact and communication with the GIM team responsible for patient care. ${ }^{8}$

Little research exists to assess whether bedspacing compromises quality of care or patient outcomes. In other areas of medicine, patients who are not cared for in the appropriate specialised setting may have worse quality of care and outcomes; for example, stroke patients not on specialised stroke services ${ }^{9}$ and haemodialysis patients on surgical services. ${ }^{10}$ Similar issues may apply to bedspaced GIM patients.

This study aimed to evaluate the relationship between bedspacing of GIM patients and inhospital mortality.

\section{METHODS}

Design

We conducted a retrospective cohort study using data collected during 2015 
at a large Canadian tertiary care hospital. Ethical approval was obtained from the institution's research ethics committee. We based our study reporting on the REporting of studies Conducted using Observational Routinely-collected health Data (RECORD) guidelines for observational studies using routinely collected data. $^{11}$

\section{Setting}

A tertiary level, acute-care, university-affiliated teaching hospital with a large catchment area exceeding 500000 people in Canada served as the study setting. The hospital has 440 inpatient beds and admits more than 22000 inpatients each year.

The GIM service has 68 beds for four clinical teaching unit (CTU) teams, which consist of a staff physician, a third year internal medicine resident, a second year internal medicine resident, two to three first year residents and two to three medical student clerks. The CTU teams change every 4 weeks. Staff physicians on CTU teams rotate every 2 weeks.

\section{Patient population}

We included consecutive adult patients admitted to the four GIM CTU teams at the hospital from 1 January 2015 to 1 January 2016. Patients were excluded if they had any of the following:

- Admission to the medical short stay team (anticipated length of stay $<72$ hours)

- Located in the step down intensive care unit

- Transfer to another service during hospital admission

- Death, discharge or leaving against medical advice before being transferred to a ward bed

\section{Data sources}

Data were obtained from patient electronic medical records and the Discharge Abstract Database, an administrative database collected for all hospital discharges and maintained by the Canadian Institute of Health Information (CIHI). ${ }^{12}$ Data were collected on patient demographics, admission diagnosis, comorbidities, death in hospital and details of discharge from hospital.

\section{Admission and bedspacing}

Patients were admitted under one of four CTU teams. Patient assignment to CTU teams was based on day of admission.

On admission, patients were typically transferred from the ED to the GIM ward. When admission numbers exceeded assigned GIM ward bed capacity, the patient flow manager secured a bed on an off-service ward based on services with available beds (with medical subspecialty wards given priority over surgical wards) and length of time the patient was in the ED since admission. In principle according to hospital guidelines, patients' reasons for admission, severity of illness, comorbidities, CTU team assignment, plans of care in hospital and discharge dispositions were not considered in this decision.

The two assigned GIM wards with 68 beds were located on geographically consolidated hospital wings (wards $\mathrm{A}$ and $\mathrm{B}$ ). If all beds were occupied on the assigned GIM wards, patients would be bedspaced to off-service ward beds. These patients were defined as bedspaced patients.

The medicine off-service wards included:

C: Medicine Short Stay Unit, Alternate Level of Care patients

F: Cardiology

I: Neurology, Neurosurgery

D: Haematology/Oncology, Medical Oncology, Radiation Oncology, Palliative Care

The surgery off-service wards included:

H: Cardiac Surgery, Thoracic Surgery, Vascular Surgery

E: Gynaecology Oncology, Plastic Surgery, Urology

G: Otolaryngology, General Surgery

J: Orthopaedic Surgery

The CTU teams are responsible for both the patients on assigned GIM wards and those on off-service wards admitted under their team. Allied health professionals (including nurses, respiratory therapists, physiotherapists, occupational therapists and social workers) are instead organised by ward location. Therefore, the off-service ward's allied health team would care for bedspaced patients.

Patients on assigned GIM wards were sometimes bedspaced to an off-service wards when they had their medical issues addressed and were awaiting disposition to free up assigned GIM ward beds for patients with active medical issues.

Patients' room locations were extracted from the hospital database to classify patients as being either on an assigned GIM ward or bedspaced. If a patient was transferred to another room, the last room location temporally closest to the end of their hospital stay (ie, death or discharge) would be recorded as their room, because the last room would have more impact on death or discharge compared with previous room locations.

\section{Variable definitions}

Capacity ratio was defined as the number of GIM inpatients (off-service and assigned GIM wards) divided by total capacity of assigned GIM wards (68 beds) on day of admission for each patient.

Case mix group (CMG) and resource intensity weight (RIW) were based on CMG methodology as described by CIHI. ${ }^{13-16}$ Admission diagnoses were organised into CMGs based on International Classification of Disease 10th Revision Canadian version (ICD-10-CA) codes, ${ }^{17}$ complications and procedure codes, while RIW was a weighted summary measure representing the relative value of resources a patient was expected to consume based on their age, CMG and comorbidities. 
ICD-10-CA diagnosis codes present at and after admission for each patient were used to calculate the Charlson Comorbidity Index (CCI ${ }^{18}$ using an established coding algorithm. ${ }^{19}$

\section{Outcomes}

The primary outcome was all-cause inhospital mortality. Patients were followed until death in hospital, discharge, or for up to 365 days following hospital admission, whichever came first. Length of stay was calculated as time from admission to discharge or death in hospital. Readmissions to the same hospital within 30 days were recorded for patients who were discharged alive.

\section{Statistical analysis}

A Cox proportional hazards model was used to characterise inhospital mortality. The survival analysis assumed non-informative censoring. ${ }^{20}$ The prognosis of patients who were discharged may be different than that of patients who remained hospitalised. The potential impact of informative censoring was addressed in a competing risk model that accounted for competing risk events that would preclude the event of interest. ${ }^{20}$ Specifically, as a secondary analysis, a competing risk model was used to describe inhospital mortality and time to discharge, where possible end points included being alive in hospital on day 365, dying in hospital or being discharged alive. Based on a cumulative incidence function, a subdistribution HR (sHR) was calcu lated based on the Fine and Gray model. ${ }^{21}$ Assumption of proportional hazard was tested based on weighted Schoenfeld residuals for the Cox proportional hazards ${ }^{22}$ and competing risk models. ${ }^{23}$ To account for non-proportional hazards, an interaction of bedspacing variable with time in a linear relationship was added in the Cox proportional hazards and competing risk models. ${ }^{24}$

As sensitivity analyses, a propensity score for room allocation (bedspaced vs assigned GIM ward) was estimated using a multivariable logistic regression model. ${ }^{25}$ The following covariates were included in the model : age, sex, admission month, admission on a weekend, capacity ratio, cumulative CCI score, individual CCI comorbidity, RIW and CMG. CMG had a factor for each of the 52 most common groups, which accounted for approximately $80 \%$ of all admissions. Bedspaced patients were matched in a 1:1 ratio to assigned GIM ward patients using nearest neighbour matching with a specified calliper width of 0.2 times SD of the logit of the propensity score. ${ }^{26}$ Covariate balance between the two groups was assessed by standardised difference with a threshold of 0.10 for significant imbalance. ${ }^{27}$ The two groups matched by propensity scores were compared using the Cox proportional hazards and competing risk models.

As another sensitivity analysis, bedspaced patients were matched to assigned GIM ward patients in a
1:1 ratio, so that each matched pair was admitted in the same 4-week rotation block under the same CTU team with the same CMG. This ensured the same CTU team for each matched pair. In cases where multiple matched pair combinations were possible, the matched pair with the closest admission dates was selected. Thus, each matched pair was admitted under the same CTU team at a similar time to reflect similar workload. The two groups were compared with the Cox proportional hazards and competing risk models.

Our study data were complete without any missing data, so statistical handling of missing data was not applicable.

All reported CIs were two-sided 95\% intervals and all tests were two-sided with a $\mathrm{P}<0.05$ significance level. All analyses were done with R V.3.2.3 (R Foundation for Statistical Computing, Vienna, Austria). Matching was done using the package matchit. ${ }^{28}$ Competing risk analysis was done using the packages cmprsk $^{29}$ and crrSC. ${ }^{30}$

\section{RESULTS}

\section{Patient characteristics}

From 1 January 2015 to 1 January 2016, 4925 patients were admitted under the GIM service, of which 3243 patients were included in the analysis (figure 1). Of these 3243 patients, over a third $(1125,35 \%)$ were bedspaced to off-service wards while the rest (2118, $65 \%$ ) were admitted to assigned GIM wards (table 1 and online supplementary appendix table 1). Numbers of bedspaced patients admitted under each off-service ward are listed in online supplementary appendix table 2 .

\section{Bed-spacing}

Over the 1-year period, the daily proportion of bedspaced patients had a median of $32 \%$ (IQR $28 \%-35 \%)$, minimum of $19 \%$ and maximum of $47 \%$ (online supplementary appendix figure 1). Daily numbers of GIM inpatients were consistently over the capacity of 68 patients except for 5 days in May (online supplementary appendix figure 2).

Bed moves were uncommon and occurred equally in both directions. Only 365 (11\%) patients were on different wards at time of discharge or death than their admission wards: 195 (6\%) were originally bedspaced and then transferred to assigned GIM wards, while $170(5 \%)$ were originally on assigned GIM wards and then bedspaced to off-service wards.

\section{Outcomes}

Of 3243 GIM inpatients, $176(5 \%)$ patients died in hospital including 88/1125 (8\%) bedspaced patients and 88/2118 (4\%) assigned GIM wards patients. Inhospital mortality rates for individual wards and each CCI strata are listed in online supplementary appendix tables 2 and 3, respectively. Deaths occurring among 


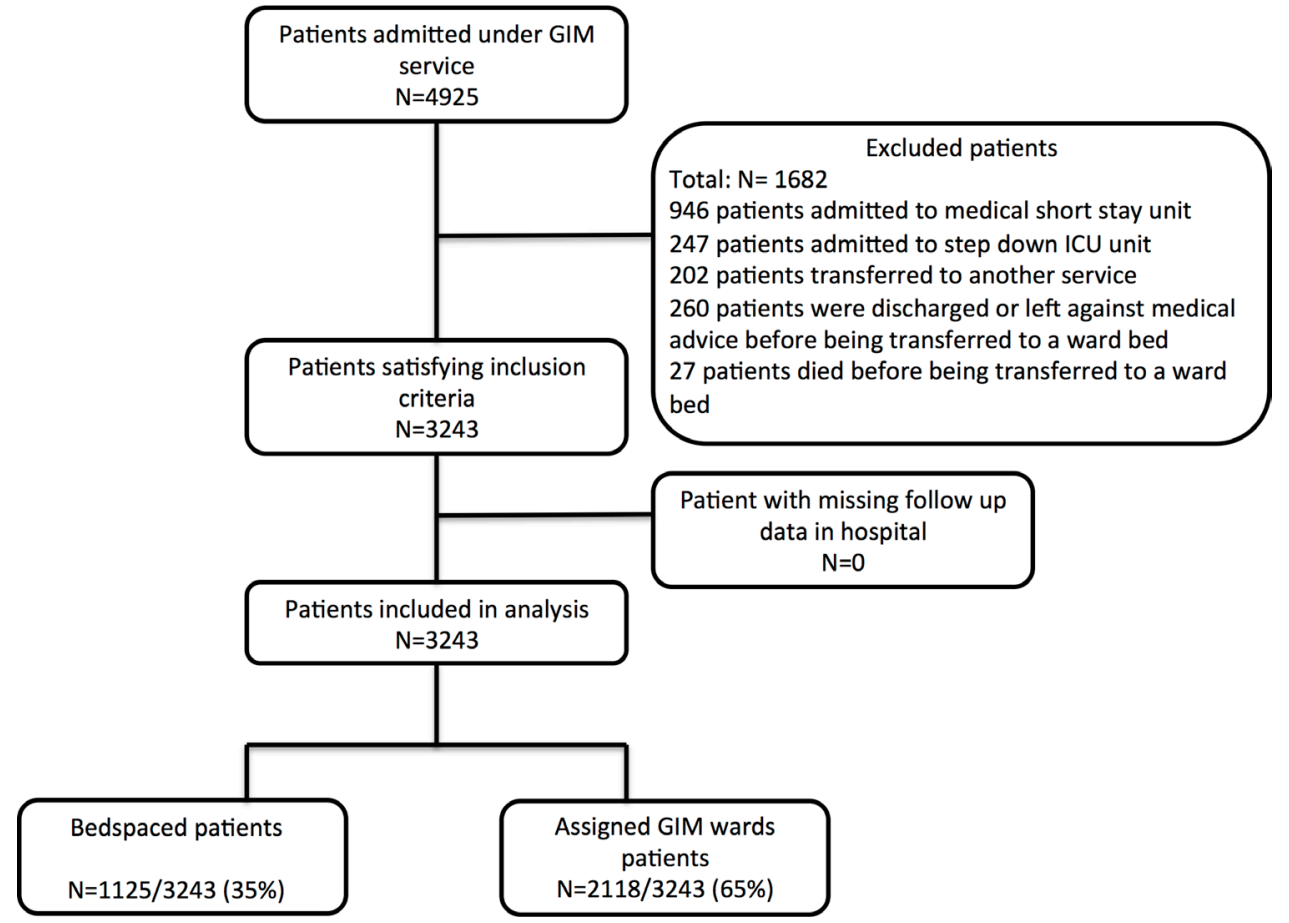

Figure 1 Flow diagram of patients included in the study. GIM, general internal medicine; ICU, intensive care unit.

assigned GIM ward and bedspaced patients are illustrated in online supplementary appendix figure 3 .

Of the 3067 patients who were discharged alive, 205/1037 (20\%) bedspaced patients and 372/2030 $(18 \%)$ assigned GIM wards patients were readmitted to the same hospital within 30 days $(\mathrm{P}=0.3582)$.

In an unadjusted Cox proportional hazards model, bedspaced patients had significantly greater inhospital mortality than assigned GIM wards patients (HR 2.24; 95\% CI 1.67 to 3.02; $\mathrm{P}<0.0001)$. Testing for non-proportionality was significant $(\mathrm{P}=0.0040)$, indicating that the relationship between bedspacing and death was time-dependent. After adding an interaction term of bedspacing with time, the HR for mortality of bedspaced patients was 3.42 (95\% CI 2.23 to 5.26; $\mathrm{P}<0.0001)$ at admission, which then decreased by HR of 0.97 (95\% CI 0.94 to $0.99 ; \mathrm{P}=0.0133$ ) per day. The HRs for time periods of 0-7 days, 7-14 days, 14-21 days and 21-28 days were 3.26 (95\% CI 2.10 to 5.07), 2.68 (95\% CI 1.39 to 5.16), 1.43 (95\% CI 0.53 to 3.86 ) and 1.16 (95\% CI 0.40 to 3.34 ), respectively.

Cumulative incidence functions describing dying in hospital and being discharged alive for bedspaced and GIM assigned wards patients are shown in figure 2. In an unadjusted competing risk model, bedspaced patients had a significantly higher risk of inhospital mortality than assigned GIM wards patients with an sHR of 1.94 (95\% CI 1.44 to $2.61 ; \mathrm{P}<0.0001)$ for dying in hospital and an sHR of 0.98 (95\% CI 0.90 to 1.06; $\mathrm{P}=0.5656$ ) for being discharged alive. Testing for non-proportionality was significant for a linear relationship with time $(\mathrm{P}<0.0001)$. After adding an interaction term of bedspacing with time, the sHR for dying in hospital of bedspaced patients was 3.18 (95\% CI 2.03 to $4.98 ; \mathrm{P}<0.0001)$ at admission, which then decreased by an sHR of 0.96 (95\% CI 0.93 to 0.99 ; $\mathrm{P}=0.0124)$ per day. The sHR of bedspaced patients for being discharged alive was 1.14 (95\% CI 1.02 to $1.26 ; \mathrm{P}=0.0210)$ at admission, which then decreased by an sHR of 0.98 (95\% CI 0.98 to $0.99 ; \mathrm{P}=0.0002)$ per day.

\section{Propensity score matching}

Based on propensity score, 1093 bedspaced patients were matched to 1093 assigned GIM wards patients (table 2 and online supplementary appendix table 4). The maximum standardised difference of matched variables was $0.0579(5.79 \%)$, reflecting good balance on measured baseline characteristics.

In the propensity-matched sample, 138/2186 (6\%) patients died in hospital: 87/1093 (8\%) for bedspaced patients and 51/1093 (5\%) for assigned GIM wards patients.

In a Cox proportional hazards model using the propensity-matched sample, the HR for mortality of bedspaced patients was 3.20 (95\% CI 1.92 to 5.33; $\mathrm{P}<0.0001)$ at admission, which then decreased by an $\mathrm{HR}$ of 0.96 (95\% CI 0.94 to $0.99 ; \mathrm{P}=0.0146)$ per day.

In a competing risk model using the propensity-matched sample, bedspaced patients had an sHR for inhospital mortality of 2.83 (95\% CI 1.67 to 4.79; $\mathrm{P}=0.0001)$ at admission, which then decreased by an sHR of 0.96 (95\% CI 0.93 to $1.00 ; \mathrm{P}=0.0302)$ per day. The sHR for discharged alive of bedspaced patients was $1.13(95 \%$ CI 1.00 to $1.27 ; \mathrm{P}=0.0530)$ 
Table 1 Baseline characteristics of bedspaced and assigned general internal medicine (GIM) wards patients

\begin{tabular}{|c|c|c|c|c|}
\hline & $\begin{array}{l}\text { All patients } \\
(\mathrm{n}=3243)\end{array}$ & $\begin{array}{l}\text { Bedspaced patients } \\
(\mathrm{n}=1125)\end{array}$ & $\begin{array}{l}\text { Assigned GIM ward } \\
\text { patients }(n=2118)\end{array}$ & $\begin{array}{l}\text { Bedspaced versus assigned } \\
\text { GIM standardised difference }\end{array}$ \\
\hline \multicolumn{5}{|l|}{ Demographics } \\
\hline Male & $1631(50.3 \%)$ & $578(51.4 \%)$ & $1053(49.7 \%)$ & 0.0332 \\
\hline Age median (IQR) & $71.00(59.00-81.00)$ & $71.00(57.00-81.00)$ & $72.00(59.00-82.00)$ & 0.1010 \\
\hline \multicolumn{5}{|l|}{ Length of stay } \\
\hline Length of stay, days: median (IQR) & $5.72(3.38-10.91)$ & $5.31(3.00-9.65)$ & $5.97(3.48-11.80)$ & 0.1119 \\
\hline \multicolumn{5}{|l|}{ Admission day } \\
\hline Weekend (Saturday or Sunday) & $838(25.8 \%)$ & $317(28.2 \%)$ & $521(24.6 \%)$ & 0.0813 \\
\hline \multicolumn{5}{|l|}{ Admission month } \\
\hline January & $271(8.4 \%)$ & $107(9.5 \%)$ & $164(7.7 \%)$ & 0.0630 \\
\hline February & $231(7.1 \%)$ & $82(7.3 \%)$ & $149(7.0 \%)$ & 0.0098 \\
\hline March & $282(8.7 \%)$ & $85(7.6 \%)$ & $197(9.3 \%)$ & 0.0629 \\
\hline April & $246(7.6 \%)$ & $69(6.1 \%)$ & $177(8.4 \%)$ & 0.0859 \\
\hline May & $256(7.9 \%)$ & $83(7.4 \%)$ & $173(8.2 \%)$ & 0.0295 \\
\hline June & $291(9.0 \%)$ & $111(9.9 \%)$ & $180(8.5 \%)$ & 0.0474 \\
\hline July & $297(9.2 \%)$ & $96(8.5 \%)$ & $201(9.5 \%)$ & 0.0334 \\
\hline August & $301(9.3 \%)$ & $91(8.1 \%)$ & $210(9.9 \%)$ & 0.0638 \\
\hline September & $250(7.7 \%)$ & $104(9.2 \%)$ & $146(6.9 \%)$ & 0.0864 \\
\hline October & $281(8.7 \%)$ & $104(9.2 \%)$ & $177(8.4 \%)$ & 0.0313 \\
\hline November & $266(8.2 \%)$ & $94(8.1 \%)$ & $172(8.4 \%)$ & 0.0085 \\
\hline December & $271(8.4 \%)$ & $99(8.8 \%)$ & $172(8.1 \%)$ & 0.0244 \\
\hline Capacity ratio median (IQR) & $1.34(1.25-1.41)$ & $1.35(1.26-1.41)$ & $1.34(1.25-1.41)$ & 0.0396 \\
\hline \multicolumn{5}{|l|}{ Clinical teaching unit (CTU) team } \\
\hline A & $820(25.3 \%)$ & $264(23.5 \%)$ & $556(26.3 \%)$ & 0.0644 \\
\hline B & $786(24.2 \%)$ & $248(22.0 \%)$ & $538(25.4 \%)$ & 0.0790 \\
\hline C & $827(25.5 \%)$ & $315(28.0 \%)$ & $512(24.2 \%)$ & 0.0872 \\
\hline D & $810(25.0)$ & $298(26.5 \%)$ & $512(24.2 \%)$ & 0.0533 \\
\hline \multicolumn{5}{|l|}{ Charlson Comorbidity Index Score } \\
\hline 0 & $888(27.4 \%)$ & $324(28.8 \%)$ & $564(26.6 \%)$ & 0.0485 \\
\hline 1 & $708(21.8 \%)$ & $236(21.0 \%)$ & $472(22.3 \%)$ & 0.0318 \\
\hline$>=2$ & $1647(50.8 \%)$ & $565(50.2 \%)$ & $1082(51.1 \%)$ & 0.0173 \\
\hline Resource intensity weight (RIW) Median (IQR) & $1.08(0.70-1.90)$ & $1.04(0.69-1.72)$ & $1.11(0.71-2.01)$ & 0.0757 \\
\hline \multicolumn{5}{|l|}{ Top seven case mix group (admission diagnosis) } \\
\hline 139 Chronic obstructive pulmonary disease & $313(9.7 \%)$ & $97(8.6 \%)$ & $216(10.2 \%)$ & 0.0540 \\
\hline 138 Viral/unspecified pneumonia & $188(5.8 \%)$ & $62(5.5 \%)$ & $126(6.0 \%)$ & 0.0188 \\
\hline 487 Lower urinary tract infection & $152(4.7 \%)$ & $37(3.3 \%)$ & $115(5.4 \%)$ & 0.1050 \\
\hline 196 Heart failure without cardiac catheter & $125(3.9 \%)$ & $42(3.7 \%)$ & $83(3.9 \%)$ & 0.0097 \\
\hline 477 Renal failure & $110(3.4 \%)$ & $41(3.6 \%)$ & $69(3.3 \%)$ & 0.0212 \\
\hline 254 Gastrointestinal haemorrhage & $88(2.7 \%)$ & $41(3.6 \%)$ & $47(2.2 \%)$ & 0.0846 \\
\hline 437 Diabetes & $76(2.3 \%)$ & $25(2.2 \%)$ & $51(2.4 \%)$ & 0.0123 \\
\hline
\end{tabular}

For full list of Charlson Comorbidity Index comorbidities and top 52 case mix groups (CMGs), please see online supplementary appendix table 1.

at admission, which then decreased by an sHR of 0.99 (95\% CI 0.98 to $1.00 ; \mathrm{P}=0.0038$ ) per day.

\section{Pair matching}

Matching by 4 -week rotation blocks, CTU team and CMG, 456 bedspaced patients were matched to 456 assigned GIM wards patients (table 3 and online supplementary appendix table 5). Although the two groups were not matched by comorbidities, the proportions of patients with CCI comorbidities were similar between the two groups. The maximum standardised difference of comorbidities was 0.1087 . Among matched pairs, the median difference in days between admission dates was 5.00 days (IQR 2.00-11.00 days). Of the 456 matched pairs, 168 (37\%) pairs were admitted in the same week.

In the paired matching sample, 50/912 (5\%) patients died in hospital: 36/456 (8\%) bedspaced patients and 14/456 (3\%) assigned GIM wards patients.

In a Cox proportional hazards model, compared with assigned GIM wards patients, the HR for mortality of bedspaced patients was 3.84 (95\% CI 1.42 to 10.38 ; $\mathrm{P}=0.0080)$ at admission, which then decreased by an HR of 0.98 (95\% CI 0.92 to $1.05 ; \mathrm{P}=0.5485)$ per day. 
Cumulative incidence of discharge alive versus death

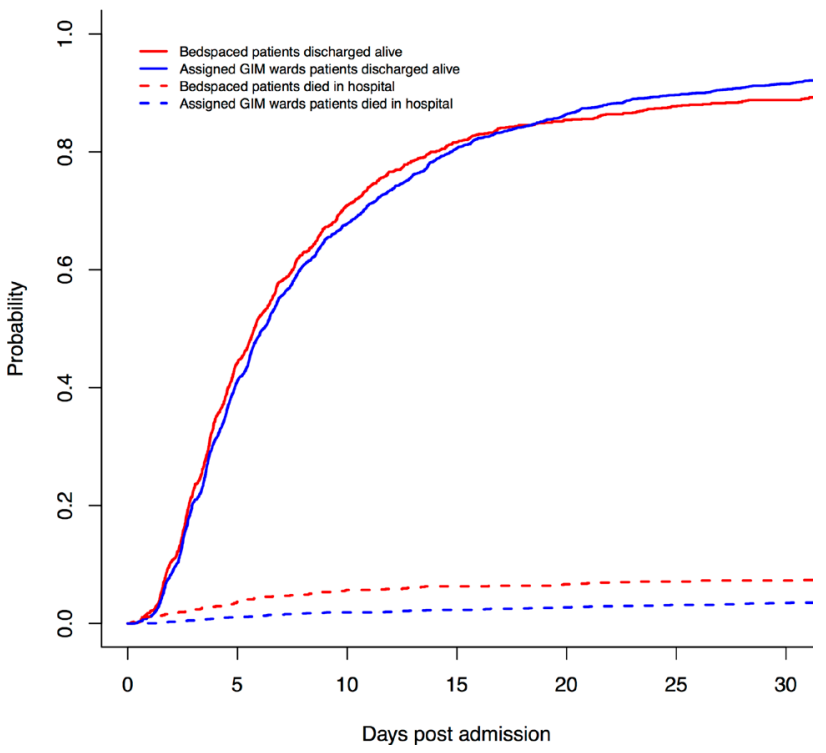

Figure 2 Cumulative incidence function curve of bedspaced and assigned general internal medicine (GIM) wards patients.

In a competing risk model, bedspaced patients had an sHR for inhospital mortality of 3.73 (95\% CI 1.38 to $10.09 ; \mathrm{P}=0.0096)$ at admission, which then decreased by an sHR of 0.97 (95\% CI 0.91 to 1.04; $\mathrm{P}=0.3589$ ) per day. The sHR of bedspaced patients for being discharged alive was 1.11 (95\% CI 0.90 to 1.37; $\mathrm{P}=0.3365)$ at admission, which decreased by an sHR of 0.98 (95\% CI 0.96 to $1.00 ; \mathrm{P}=0.0477)$ per day.

\section{Sensitivity analyses}

Comparison of bedspaced and assigned GIM wards patients using restricted mean time survival that did not assume proportional hazards again demonstrated shorter survival time for bedspaced patients (online supplementary appendix text 1).

Comparison of bedspaced and assigned GIM wards patients based on their first ward bed (instead of ward bed at discharge or death) yielded similar results (online supplementary appendix table 6).

An analysis of matched pairs admitted in the same week (to ensure the same staff physician for both matched patients)showed similar results (online supplementary appendix table 7).

\section{DISCUSSION}

In this retrospective cohort study, the risk for inhospital mortality among bedspaced patients was approximately three times that of patients admitted to assigned GIM wards in the first week of admission, which then decreased to approximately the same risk by the third week. This result was consistent across multiple analyses that employed competing risk models, propensity score matching and pair matching.
Table 2 Propensity-matched bedspaced and assigned general internal medicine (GIM) wards patients

\begin{tabular}{|c|c|c|c|}
\hline & $\begin{array}{l}\text { Bedspaced patients } \\
(n=1093)\end{array}$ & $\begin{array}{l}\text { Assigned GIM wards } \\
\text { patients }(n=1093)\end{array}$ & $\begin{array}{l}\text { Standardised } \\
\text { difference }\end{array}$ \\
\hline \multicolumn{4}{|l|}{ Demographics } \\
\hline Male & $561(51.3 \%)$ & $572(52.3 \%)$ & 0.0201 \\
\hline Age median (IQR) & $71.00(58.00-81.00)$ & $71.00(57.00-81.00)$ & 0.0150 \\
\hline \multicolumn{4}{|l|}{ Length of stay } \\
\hline $\begin{array}{l}\text { Length of stay, days: } \\
\text { median (IQR) }\end{array}$ & $5.43(3.01-9.74)$ & $6.29(3.50-11.86)$ & 0.1011 \\
\hline \multicolumn{4}{|l|}{ Admission day } \\
\hline $\begin{array}{l}\text { Weekend (Saturday or } \\
\text { Sunday) }\end{array}$ & $307(28.1 \%)$ & $301(27.5 \%)$ & 0.0123 \\
\hline \multicolumn{4}{|l|}{ Admission month } \\
\hline January & $104(9.5 \%)$ & $112(10.3 \%)$ & 0.0245 \\
\hline February & $81(7.4 \%)$ & $82(7.5 \%)$ & 0.0035 \\
\hline March & $83(7.6 \%)$ & $67(6.1 \%)$ & 0.0579 \\
\hline April & $66(6.0 \%)$ & $70(6.4 \%)$ & 0.0152 \\
\hline May & $81(7.4 \%)$ & $80(7.3 \%)$ & 0.0035 \\
\hline June & $107(9.8 \%)$ & $105(9.6 \%)$ & 0.0062 \\
\hline July & $94(8.6 \%)$ & $104(9.5 \%)$ & 0.0319 \\
\hline August & $90(8.2 \%)$ & $75(6.9 \%)$ & 0.0520 \\
\hline September & $102(9.3 \%)$ & $94(8.6 \%)$ & 0.0256 \\
\hline October & $96(8.8 \%)$ & $102(9.3 \%)$ & 0.0191 \\
\hline November & $94(8.6 \%)$ & $105(9.6 \%)$ & 0.0350 \\
\hline December & $95(8.7 \%)$ & $97(8.9 \%)$ & 0.0065 \\
\hline $\begin{array}{l}\text { Capacity ratio median } \\
\text { (IQR) }\end{array}$ & $1.35(1.26-1.41)$ & $1.34(1.26-1.41)$ & 0.0096 \\
\hline \multicolumn{4}{|c|}{ Clinical teaching unit (CTU) team } \\
\hline A & $263(24.1 \%)$ & $296(27.1 \%)$ & 0.0692 \\
\hline B & $242(22.1 \%)$ & $269(24.6 \%)$ & 0.0584 \\
\hline C & $297(27.2 \%)$ & $280(25.6 \%)$ & 0.0353 \\
\hline D & $291(26.6 \%)$ & $248(22.7 \%)$ & 0.0914 \\
\hline \multicolumn{4}{|c|}{ Charlson Comorbidity Index (CCI) Score } \\
\hline 0 & $314(28.7 \%)$ & $300(27.5 \%)$ & 0.0285 \\
\hline 1 & $232(21.2 \%)$ & $216(19.8 \%)$ & 0.0363 \\
\hline$>=2$ & $547(50.1 \%)$ & $577(52.8 \%)$ & 0.0549 \\
\hline $\begin{array}{l}\text { Resource intensity } \\
\text { weight (RIW) } \\
\text { Median (IQR) }\end{array}$ & $1.05(0.69-1.72)$ & $1.09(0.70-2.04)$ & 0.0191 \\
\hline \multicolumn{4}{|c|}{ Top seven case mix group (Admission diagnosis) } \\
\hline $\begin{array}{l}139 \text { Chronic obstructive } \\
\text { pulmonary disease }\end{array}$ & $97(8.9 \%)$ & $98(9.0 \%)$ & 0.0032 \\
\hline $\begin{array}{l}138 \text { Viral/unspecified } \\
\text { pneumonia }\end{array}$ & $62(5.7 \%)$ & $55(5.0 \%)$ & 0.0285 \\
\hline $\begin{array}{l}487 \text { Lower urinary tract } \\
\text { infection }\end{array}$ & $37(3.4 \%)$ & $39(3.6 \%)$ & 0.0100 \\
\hline $\begin{array}{l}196 \text { Heart failure without } \\
\text { cardiac catheter }\end{array}$ & $42(3.8 \%)$ & $50(4.6 \%)$ & 0.0365 \\
\hline 477 Renal failure & $41(3.8 \%)$ & $43(3.9 \%)$ & 0.0095 \\
\hline $\begin{array}{l}254 \text { Gastrointestinal } \\
\text { haemorrhage }\end{array}$ & $41(3.8 \%)$ & $39(3.6 \%)$ & 0.0097 \\
\hline 437 Diabetes & $25(2.3 \%)$ & $26(2.4 \%)$ & 0.0061 \\
\hline
\end{tabular}
please see online supplementary appendix table 4.

To our knowledge, this is the first study to document heightened mortality associated with the practice of bedspacing.

The CCI Score and length of stay in our study were lower than those reported in some individual tertiary Canadian centres, ${ }^{31}{ }^{32}$ but higher than the average reported in a multicentre study of 11 hospitals in Ontario. ${ }^{33}$ Our inhospital mortality rate of $5 \%$ 
Table 3 Bedspaced and assigned general internal medicine (GIM) wards patients pair matched by rotation block, Clinical teaching unit (CTU) team and case mix group (CMG)

\begin{tabular}{|c|c|c|c|}
\hline & $\begin{array}{l}\text { Bedspaced patients } \\
(n=456)\end{array}$ & $\begin{array}{l}\text { Assigned GIM wards } \\
\text { patients }(n=456)\end{array}$ & $\begin{array}{l}\text { Standardised } \\
\text { difference }\end{array}$ \\
\hline \multicolumn{4}{|l|}{ Demographics } \\
\hline Male & $232(50.9 \%)$ & $222(48.7 \%)$ & 0.0439 \\
\hline Age median (IQR) & $73.00(61.00-82.25)$ & $73.00(61.00-83.00)$ & 0.0393 \\
\hline \multicolumn{4}{|l|}{ Length of stay } \\
\hline $\begin{array}{l}\text { Length of stay, days: } \\
\text { median (IQR) }\end{array}$ & $4.97(2.96-8.84)$ & $5.54(3.31-9.98)$ & 0.0774 \\
\hline \multicolumn{4}{|l|}{ Admission day } \\
\hline $\begin{array}{l}\text { Weekend (Saturday or } \\
\text { Sunday) }\end{array}$ & $123(27.0 \%)$ & $112(24.6 \%)$ & 0.0552 \\
\hline \multicolumn{4}{|l|}{ Admission month } \\
\hline January & $35(7.7 \%)$ & $37(8.1 \%)$ & 0.0163 \\
\hline February & $41(9.0 \%)$ & $31(6.8 \%)$ & 0.0814 \\
\hline March & $35(7.7 \%)$ & $46(10.1 \%)$ & 0.0849 \\
\hline April & $33(7.2 \%)$ & $32(7.0 \%)$ & 0.0085 \\
\hline May & $29(6.4 \%)$ & $27(5.9 \%)$ & 0.0183 \\
\hline June & $37(8.1 \%)$ & $37(8.1 \%)$ & 0.0000 \\
\hline July & $45(9.9 \%)$ & $46(10.1 \%)$ & 0.0073 \\
\hline August & $34(7.5 \%)$ & $39(8.6 \%)$ & 0.0404 \\
\hline September & $45(9.9 \%)$ & $37(8.1 \%)$ & 0.0614 \\
\hline October & $39(8.6 \%)$ & $45(9.9 \%)$ & 0.0455 \\
\hline November & $45(9.9 \%)$ & $39(8.6 \%)$ & 0.0455 \\
\hline December & $38(8.3 \%)$ & $40(8.8 \%)$ & 0.0157 \\
\hline $\begin{array}{l}\text { Capacity ratio median } \\
\text { (IQR) }\end{array}$ & $1.35(1.26-1.41)$ & $1.34(1.26-1.43)$ & 0.0346 \\
\hline \multicolumn{4}{|l|}{ CTU team } \\
\hline A & $122(26.8 \%)$ & $122(26.8 \%)$ & 0.0000 \\
\hline B & $107(23.5 \%)$ & $107(23.5 \%)$ & 0.0000 \\
\hline$C$ & $113(24.8 \%)$ & $113(24.8 \%)$ & 0.0000 \\
\hline D & $114(25.0 \%)$ & $114(25.0 \%)$ & 0.0000 \\
\hline \multicolumn{4}{|c|}{ Charlson Comorbidity Index (CCI) Score } \\
\hline 0 & $113(24.8 \%)$ & $118(25.9 \%)$ & 0.0252 \\
\hline 1 & $121(26.5 \%)$ & $101(22.2 \%)$ & 0.1023 \\
\hline$>=2$ & $222(48.7 \%)$ & $237(52.0 \%)$ & 0.0658 \\
\hline $\begin{array}{l}\text { Resource intensity weight } \\
\text { (RIW) } \\
\text { Median (IQR) }\end{array}$ & $0.97(0.69-1.51)$ & $1.02(0.69-1.73)$ & 0.0180 \\
\hline \multicolumn{4}{|c|}{ Top seven case mix group (admission diagnosis) } \\
\hline $\begin{array}{l}139 \text { Chronic obstructive } \\
\text { pulmonary disease }\end{array}$ & $83(18.2 \%)$ & $83(18.2 \%)$ & 0.0000 \\
\hline $\begin{array}{l}138 \text { Viral/unspecified } \\
\text { pneumonia }\end{array}$ & $52(11.4 \%)$ & $52(11.4 \%)$ & 0.0000 \\
\hline $\begin{array}{l}487 \text { Lower urinary tract } \\
\text { infection }\end{array}$ & $32(7.0 \%)$ & $32(7.0 \%)$ & 0.0000 \\
\hline $\begin{array}{l}196 \text { Heart failure without } \\
\text { cardiac catheter }\end{array}$ & $31(6.8 \%)$ & $31(6.8 \%)$ & 0.0000 \\
\hline 477 Renal failure & $23(5.0 \%)$ & $23(5.0 \%)$ & 0.0000 \\
\hline $\begin{array}{l}254 \text { Gastrointestinal } \\
\text { haemorrhage }\end{array}$ & $20(4.4 \%)$ & $20(4.4 \%)$ & 0.0000 \\
\hline 437 Diabetes & $15(3.3 \%)$ & $15(3.3 \%)$ & 0.0000 \\
\hline
\end{tabular}

For full list of Charlson Comorbidity Index comorbidities and top 52 case mix groups (CMGs), please see online supplementary appendix table 7 .

approximates the inhospital mortality rate on GIM services in Canadian academic tertiary acute care hospitals. $^{32}$

This study has several strengths. First, the large sample size allowed for precise estimates. Second, our study recruited patients over a 1-year period. The admitting diagnoses, prognoses and outcomes may differ depending on month and season. Data over a 1-year period allowed examination and adjustment for trends over time. Third, the findings remained robust using Cox proportional hazards and competing risk models with adjustment for many potential confounders using propensity score matching and pair matching. The propensity score and pair matching ensured that the two groups were balanced in terms of prognostic factors including demographics, comorbidity, care provider, workload, time of admission and reason for admission.

Several study limitations merit emphasis. First, this study used data from a retrospective discharge database. The database was not created specifically for our research question. However, the data collection and verification were rigorous, consistent and complete, as it was based on a standardised protocol by CIHI. ${ }^{12}$ All of the data relevant to our research were collected by the database.

Second, there may be residual confounders. As an example, bedspacing may be more common during periods of higher patient influx, when the heavier caseload may have led to worse outcomes. However, the temporal trend showed a constant trend in patient volume above capacity of 68 beds and the proportion of bedspaced patients with few significant spikes (online supplementary appendix figures 1 and 2). Moreover, we adjusted for workload by including a capacity ratio in the propensity score and by pair matching (where each matched pair was admitted at a similar time under the same CTU team). Boarding time in the emergency room may be another confounder. Patients with longer boarding time may be more likely to be bedspaced to off-service wards, where the boarding time led to a higher mortality. We excluded patients who were discharged or died in the emergency room. Thus, all patients were alive on completion of transfer to the hospital ward. More than $85 \%$ of inhospital deaths occurred after 2 days in hospital. Since all patients were alive after transfer to the hospital ward and the majority of deaths occurred after 2 days of hospital stay, it would be unlikely for cause of death to be due to care during boarding in the emergency room and more likely for the cause of death to be related to the care received in the hospital ward. Another possible confounder would be preferential bedspacing of sicker patients, which could account for higher mortality. However, this was unlikely given that bedspacing decisions were not based on disease severity. Although disease severity was not adjusted, the comorbidity score and reason for admission were similar between the propensity-matched groups. Our primary analysis did not account for transfer of patients between off-service and assigned GIM wards. However, transfers occurred in only $11 \%$ of patients and went in both directions. Sensitivity analysis based on first ward bed yielded similar results (online supplementary appendix table 6). Transfer between the off-service and GIM wards would make the two groups more similar to one 
another making it more difficult to detect a difference, so results would be conservative.

Third, our study was based on a single academic acute care hospital, which limits the generalisability of the results.

There may be several reasons for bedspaced patients to have a higher risk of mortality. First, off-service wards were geographically separated from the CTU teams' usual rounding area, which may have decreased the frequency and duration of patient contact and interaction. Decreased patient contacts in situations such as boarding in EDs and isolation precautions for infection control have been linked to increased rates of adverse events and higher mortality. ${ }^{6}{ }^{34}$ Second, bedspacing may reduce the frequency and quality of communication between CTU medical personnel and unfamiliar allied health team members (especially nurses) who host these patients on off-service wards. Inadequate communication between nurses and physicians has been associated with higher inpatient mortality. ${ }^{35} 36$ On the GIM wards, daily 'bullet rounds' typically occur Monday to Friday. At these rounds, the medical and allied healthcare teams discuss and update patient care plans daily. An interdisciplinary approach has been shown to decrease mortality. ${ }^{37}$ These bullet rounds would omit bedspaced patients, and therefore these patients would not receive the benefits of a comprehensive team approach. Third, the allied health team members on off-service wards may provide lower quality of care due to different skill sets and lack of experience caring for GIM inpatients. Inexperience with managing specialised medical issues, such as care for haemodialysis patients on surgical wards, has led to care lapses that predispose patients to adverse events. ${ }^{10}$ Lastly, for an acutely sick GIM patient, the highest workload in terms of new investigations and clinical instability are often compressed into the first few days post admission. Bedspaced GIM patients are often bedspaced at the start of admission. Less frequent clinical monitoring by the team due to geographical barriers at this vulnerable period may increase the risk of adverse outcomes. We hypothesise that a combination of these factors may have contributed to the observed increase in mortality for bedspaced patients. The magnitude of the risk is greater than we had anticipated based on the presumed mechanisms, and there may be a complex interplay of various factors contributing to this striking increase in mortality. The limitations of this single centre study such as residual confounding or other unforeseen factors may have contributed to this surprisingly large mortality risk. Pending further study at other institutions, cautious interpretation of our results is warranted.

Our study showed that the highest risk of mortality for bedspaced patients occurred within the first week of admission. We hypothesise that internal medicine patients were most medically active within the first days of admission requiring intensive investigations and management. Bedspacing may have the most impact during this critical period of active workup and management resulting in a front-loaded mortality risk.

Interestingly, based on the competing risk model, the bedspaced patients had a slightly higher rate of discharge compared with assigned GIM patients initially at time of admission. However, this trend was not statistically significant for the propensity-matched and pair-matched analyses. It may be that the knowledge of taking up a bed from another service gave the CTU teams additional motivation to address the bedspaced patients' medical issues and discharge these patients sooner.

This study highlights the importance of managing patient flow and bed mapping. Future interventional or quasi-experimental studies may help demonstrate the impact of patient flow and bed mapping policies on patient quality of care and outcomes. The number of bedspaced off-service ward GIM patients may be a clinically important and potentially modifiable quality marker. Future hospital policies focusing on patient flow should prioritise getting patients to the appropriate assigned ward beds, which may contribute to improved patient outcomes.

Our findings should be interpreted with caution, because they are based on a single centre. Each hospital has unique features relating to hospital capacity, bed mapping, admission processes, organisation of healthcare teams and training of healthcare professionals. Small single centred studies tend to overinflate the estimated effect due to a greater risk of bias. ${ }^{38}{ }^{39}$ It is not uncommon for results of non-randomised studies to be contradicted by future studies. ${ }^{40}$ Therefore, future studies with multiple sites including both academic and community hospitals are necessary to ensure the generalisability of these findings. Future studies should also examine reasons for the differences in mortality, to help design strategies to minimise risk when bedspacing is deemed unavoidable.

In conclusion, we observed substantially higher inhospital mortality for GIM patients bedspaced to off-service wards. Future studies in other hospitals should help clarify mechanisms that influence the association between bedspacing and adverse outcomes including mortality. In this way, we may be able to identify modifiable contributors to this relationship and thereby improve patient safety.

Acknowledgements Parts of this manuscript are based on data and information compiled and provided by the Canadian Institute for Health Information (CIHI). However, the analyses, conclusions, opinions, and statements expressed herein are those of the authors and not necessarily those of CIHI. No endorsement by CIHI is intended or should be inferred. We are indebted to Rod Albrough who extracted the data from the hospital database.

Contributors ADB and SSG designed the study. ADB acquired the data. ADB and GAT performed the analyses. All authors were involved in interpretation of data. ADB wrote the first 
draft of the manuscript. All authors were involved in revisions and approving the final manuscript for publication. ADB is guarantor for the manuscript.

\section{Competing interests None declared.}

Ethics approval Ethical approval was obtained from the institution's research ethics committee.

Provenance and peer review Not commissioned; externally peer reviewed.

(C) Article author(s) (or their employer(s) unless otherwise stated in the text of the article) 2018. All rights reserved. No commercial use is permitted unless otherwise expressly granted.

\section{REFERENCES}

1 Eriksson CO, Stoner RC, Eden KB, et al. The association between hospital capacity strain and inpatient outcomes in highly developed countries: a systematic review. J Gen Intern Med 2017;32:686-96.

2 Hoot NR, Aronsky D. Systematic review of emergency department crowding: causes, effects, and solutions. Ann Emerg Med 2008;52:126-36.

3 Liu SW, Chang Y, Weissman JS, et al. An empirical assessment of boarding and quality of care: delays in care among chest pain, pneumonia, and cellulitis patients. Acad Emerg Med 2011;18:1339-48.

4 White BA, Biddinger PD, Chang Y, et al. Boarding inpatients in the emergency department increases discharged patient length of stay. J Emerg Med 2013;44:230-5.

5 Viccellio A, Santora C, Singer AJ, et al. The association between transfer of emergency department boarders to inpatient hallways and mortality: a 4-year experience. Ann Emerg Med 2009;54:487-91.

6 Singer AJ, Thode HC, Viccellio P, et al. The association between length of emergency department boarding and mortality. Acad Emerg Med 2011;18:1324-9.

7 Wong HJ, Morra D, Caesar M, et al. Understanding hospital and emergency department congestion: an examination of inpatient admission trends and bed resources. CJEM 2010;12:18-26.

8 Liu J, Griesman J, Nisenbaum R, et al. Quality of care of hospitalized internal medicine patients bedspaced to non-internal medicine inpatient units. PLoS One 2014;9:e106763.

9 Foley N, Salter K, Teasell R. Specialized stroke services: a meta-analysis comparing three models of care. Cerebrovasc Dis 2007;23:194-202.

10 Harel Z, Wald R, Liu JJ, et al. Lapses in safety in end-stage renal disease patients admitted to surgical services. Hemodial Int 2012;16:286-93.

11 Benchimol EI, Smeeth L, Guttmann A, et al. The REporting of studies Conducted using Observational Routinely -collected health Data (RECORD) statement. PLoS Med 2015;12:e1001885.

12 Canadian Institute for Health Information (CIHI). Discharge Abstract Database Metadata https:/www.cihi.ca/en/types-ofcare/hospital-care/acute-care/dad-metadata (accessed 3 Oct 2017).

13 Canadian Institute for Health Information (CIHI). Case Mix Groups + https://www.cihi.ca/en/data-and-standards/standards/ case-mix/cmg (accessed 3 Oct 2017).

14 Pink GH, Bolley HB. Physicians in health care management: 3. Case Mix Groups and Resource Intensity Weights: an overview for physicians. CMAJ 1994;150:889-94.
15 Pink GH, Bolley HB. Physicians in health care management: 4. Case Mix Groups and Resource Intensity Weights: physicians and hospital funding. CMAJ 1994;150:1255-61.

16 Perry S, Homan C. Use of case mix tools for utilization management and planning. Stud Health Technol Inform 2009;143:496-500.

17 Canadian Institute for Health Information. International Statistical Classification of Diseases and Related Health Problems Tenth Revision. Canada [ICD-10-CA. Ottawa, Ontario: Canadian Institute for Health Information, 2003.

18 Charlson ME, Pompei P, Ales KL, et al. A new method of classifying prognostic comorbidity in longitudinal studies: development and validation. J Chronic Dis 1987;40:373-83.

19 Quan H, Sundararajan V, Halfon P, et al. Coding algorithms for defining comorbidities in ICD-9-CM and ICD-10 administrative data. Med Care 2005;43:1130-9.

20 Satagopan JM, Ben-Porat L, Berwick M, et al. A note on competing risks in survival data analysis. $\mathrm{Br} J$ Cancer 2004;91:1229-35.

21 Fine JP, Gray RJ. A proportional hazards model for the subdistribution of a competing risk. J Am Stat Assoc 1999;94:496-509.

22 Grambsch PM, THERNEAU TM. Proportional hazards tests and diagnostics based on weighted residuals. Biometrika 1994;81:515-26.

23 Zhou B, Fine J, Laird G. Goodness-of-fit test for proportional subdistribution hazards model. Stat Med 2013;32:3804-11.

24 Latouche A, Allignol A, Beyersmann J, et al. A competing risks analysis should report results on all cause-specific hazards and cumulative incidence functions. J Clin Epidemiol 2013;66:648-53.

25 Rubin DB. The design versus the analysis of observational studies for causal effects: parallels with the design of randomized trials. Stat Med 2007;26:20-36.

26 Austin PC. An introduction to propensity score methods for reducing the effects of confounding in observational studies. Multivariate Behav Res 2011;46:399-424.

27 Austin PC. Balance diagnostics for comparing the distribution of baseline covariates between treatment groups in propensityscore matched samples. Stat Med 2009;28:3083-107.

28 Ho D, Imai K, King G, et al. MatchIt: Nonparametric Preprocessing for Parametric Casual Inference. https:// CRAN.R-project.org $/$ package $=$ MatchIt $($ accessed 3 Oct 2017).

29 Gray B. Cmprsk: Subdistribution Analysis of Competing Risks. https://CRAN.R-project.org/package $=$ cmprsk $($ accessed 3 Oct 2017).

30 Zhou B, Latouche A. CrrSC: Competing risks regression for Stratified and Clustered data. https://CRAN.R-project.org/ package $=$ crrSC (accessed 3 Oct 2017).

31 McAlister FA, Youngson E, Bakal JA, et al. Physician experience and outcomes among patients admitted to general internal medicine teaching wards. CMAJ 2015;187:1041-8.

32 Tran K, Bell C, Stall N, et al. The effect of hospital isolation precautions on patient outcomes and cost of care: a multi-site, retrospective, propensity score-matched cohort study. J Gen Intern Med 2017;32:262-8.

33 van Walraven C, Dhalla IA, Bell C, et al. Derivation and validation of an index to predict early death or unplanned readmission after discharge from hospital to the community. CMAJ 2010;182:551-7.

34 Stelfox HT, Bates DW, Redelmeier DA. Safety of patients isolated for infection control. JAMA 2003;290:1899-905. 


\section{Original research}

35 Knaus WA, Draper EA, Wagner DP, et al. An evaluation of outcome from intensive care in major medical centers. Ann Intern Med 1986;104:410-8.

36 Tourangeau AE, Cranley LA, Jeffs L. Impact of nursing on hospital patient mortality: a focused review and related policy implications. Qual Saf Health Care 2006;15:4-8.

37 Rubenstein LZ, Josephson KR, Wieland GD, et al. Effectiveness of a geriatric evaluation unit. A randomized clinical trial. N Engl J Med 1984;311:1664-70.
38 Button KS, Ioannidis JP, Mokrysz C, et al. Power failure: why small sample size undermines the reliability of neuroscience. Nat Rev Neurosci 2013;14:365-76.

39 Dechartres A, Boutron I, Trinquart L, et al. Single-center trials show larger treatment effects than multicenter trials: evidence from a meta-epidemiologic study. Ann Intern Med 2011;155:39-51.

40 Ioannidis JP. Contradicted and initially stronger effects in highly cited clinical research. JAMA 2005;294:218-28. 